\title{
UMA VISÃO DIALÉTICA EM ANTÍGONA, DE SÓFOCLES
}

\author{
Dulcileide V. do Nascimento Braga* \\ (Universidade do Estado do Rio de Janeiro)
}

\begin{abstract}
RESUMO: Este artigo desenvolve algumas reflexões sobre a linguagem feminina atribuída às mulheres, usando como exemplo trechos do texto Antígona, de Sófocles. A análise observa as técnicas dialéticas descritas nos Tópicos de Aristóteles, salientando a importância das mesmas serem utilizadas, também, como reflexo da situação sócio-política vigente no século V a.C. Palavras-Chave: Dialética; Antígona; Persuasão.
\end{abstract}

\section{ANTIGONE DIALECTIC VIEW OF SOPHOCLES}

\begin{abstract}
This article develops some reflections on the feminine language attributed to women, using as example excerpts from Sophocles Antigone text. The analysis observes the dialectal techniques described in Aristotle's Topics, stressing the importance of their being also used as a reflection of the socio-political situation prevailing in the fifth century BC.
\end{abstract}

KEYWORDS: Dialectic; Antigone; Persuasion.

O homem segundo o conceito ocidental, criado "à imagem e semelhança de Deus", recebeu o dom maior da linguagem e, através dela, conseguiu difundir seus sentimentos e ideais, utilizando, inicialmente, a palavra falada e, posteriormente, a escrita como principal instrumento de comunicação.

Ao tomar consciência do poder que a manipulação desse dom conferia, o homem estipulou regras para o seu melhor aproveitamento, o que proporcionou o surgimento de técnicas oratórias como a retórica e a dialética, das quais obteve-se os primeiros relatos de normatização na Grécia do século V a.C. O homem, portanto, consciente da necessidade do domínio da linguagem, enquanto arte do bem falar, para o ser social, buscou cada vez mais técnicas para aperfeiçoá-la.

Os helenos foram, segundo o relato de James J. Murphy (1983, p.9), os únicos do mundo antigo a se deter na análise das diversas maneiras de comunicação entre os seres humanos, não havendo evidências destas técnicas em outras civilizações antigas. Deste modo, a retórica ficou conhecida como a arte dos discursos e a dialética como a dos diálogos. As duas, a princípio tão similares, são diferenciadas por Chaim Perelman (1996, p.40) ao afirmar que quando o discurso é conferido a um só ouvinte, em lugar de a um auditório, admite-se a superioridade da dialética, como técnica do discurso, sobre a retórica. Isso porque o ouvinte, ao interferir no discurso, transforma-o em diálogo.

\footnotetext{
*E-mail: dulcinascimentobraga@gmail.com

Principia, Rio de Janeiro, n. 41, jul.-dez., 2020. e-ISSN 2358-7326
} 
Todas as mudanças conceituais a respeito do conceito dialético estão vinculadas às questões ideológicas e culturais que envolvem determinados grupos sociais dos quais o homem é parte integrante. Por isso, buscar entender o que foi e o que se tornou no mundo atual os estudos acerca da dialética é também buscar compreender o próprio desenvolvimento do homem.

Mas qual a definição de dialética e qual seu objeto de estudo, especificamente?

Dialética é uma palavra proveniente do grego dialektiké, termo derivado do verbo dialégomai (que significa eu dialogo), cujo significado é arte do diálogo e da discussão.

Para Aristóteles (Tópicos, p.12), ela é um método investigativo que permite a qualquer falante replicar, partindo de opiniões geralmente aceitas, qualquer argumento sobre um determinado assunto que lhe seja proposto.

A sua estruturação se deu, segundo Alfredo Llanos (1988, p.11), durante o século V a.C. com os filósofos gregos da Jônia e de Éfeso e prosseguiu seu desenvolvimento em Eléa, Abdera e Atenas com Zênon, Platão e Aristóteles. No decorrer dos séculos, novos valores foram-lhe sendo acrescentados, ganhou uma nova estruturação com Kant, Hegel e Marx, passando a ser entendida, segundo Leandro Konder (1986, p.80), como o modo de pensarmos as contradições da realidade, o modo de compreendermos a realidade como essencialmente contraditória e em permanente transformação.

Esse artigo se deterá, contudo, à visão clássica de dialética, que, como arte do diálogo e da discussão, recebeu, em Platão, características distintas, ou seja, é compreendida como habilidade de discutir por perguntas ne respostas (cf. Crátilo) e também como arte de classificar os conceitos para depois examiná-los e discuti-los (cf. O Sofista).

Assim como Platão, na Antiguidade clássica, a dialética alcançou dois sentidos inteiramente opostos, que se conservaram|: um elogioso, que a converteu em lógica; e outro pejorativo, que lhe atribuiu o caráter das sutilezas e artimanhas, considerada como erística, ou arte das controvérsias. Aristóteles, no entanto, limita os caminhos trilhados pela dialética e a define como uma arte intermediária entre a retórica e a analítica.

A diferença, todavia, entre retórica e dialética encontra-se no campo das argumentações demonstrativas, das provas. A retórica conduz o ouvinte a chegar racionalmente à conclusão desejada através de uma argumentação probatória; já a dialética utiliza a persuasão psicológica, desprovida de provas, a indução lógica, para alcançar seus objetivos. A analítica, por sua vez, tem por objetivo a demonstração, isto é, a dedução que parte de premissas verdadeiras, enquanto a dialética, para Aristóteles, trata dos raciocínios que levam a opiniões prováveis, por isso é chamada por Kant de "argumentação ilusória", já que se afasta da concepção de verdade absoluta.

A Grécia do século V a.C., mais especificamente Atenas, possuidora de uma mentalidade voltada para o desenvolvimento e a ascensão social, abandona, de uma maneira geral, as investigações fenomenológicas da filosofia da natureza e busca uma educação voltada para o desenvolvimento intelectual e para o domínio da linguagem, conhecimentos considerados úteis ao ser social.

Com base nesse entendimento, Aristóteles, foi antes de tudo, segundo Paul Harvey (1985, p.55), um professor cuja prática oral deixou expressa na literatura e, consciente de que o desejo pelo saber é inato ao homem, tenta, através de suas obras demonstrar as técnicas de aquisição desse saber. Portanto, ao ter consciência de que a dialética era uma arte que merecia uma metodologia definida, o estagirita dedicou-lhe um tratado de nome Tópicos, pouco lido e discutido no seio das universidades brasileiras. Nele encontramos o método para refutar opiniões sobre qualquer assunto, mostrando que qualquer pessoa pode triunfar sobre um adversário mediante uma argumentação bem elaborada e convincente.

A dialética é, então, um método de aprimoramento da arte da palavra que visa a uma perfeita técnica do argumentar. Ela é um instrumento para destacar as relações interpessoais e 
intersociais. Através do auxílio da sua metodologia podemos observar o quanto a palavra sugere e impõe, ao mesmo tempo, sentimentos, desejos e emoções, pois, além de ser veículo de expressão, aspira a convencer e persuadir.

Discute-se, entretanto, quem teria sido o fundador desta "técnica". Para Aristóteles o seu fundador seria Zênon de Eléa, que viveu aproximadamente entre 490 a 430 a. C., e foi discípulo de Parmênides; outros autores já consideravam ser Sócrates (469- 339 a.C.) o criador desta arte.

Segundo Llanos (1988, p.11), Zênon utilizou o que ele chama de dialética subjetiva, ou dialética do pensamento humano, lugar onde se refletem as contradições do mundo externo. Seu propósito era deixar estabelecido que, mesmo existindo coisas que são ao mesmo tempo finitas ou infinitas, a realidade é a unidade. Quanto a Sócrates, seu método dialético consistia em perguntas e respostas (tudo que sabemos deste método e da pessoa de Sócrates é através de seus discípulos, Xenofonte e Platão) e dividia-se em quatro fases: a primeira é chamada de ironia, pois consistia na hipóteses de Sócrates iniciar uma discussão, aceitando sua ignorância e exaltando o mérito do oponente; a outra seria a maiêutica, ou arte de dar à luz, que auxiliava o interlocutor a produzir novos pensamentos; a indução, que consistia na procura do universal nos atos virtuosos, por meio de análise e comparações; e a definição, ou seja, a determinação do que são as coisas desprovidas de seus acidentes, mediante uma referência ao essencial, é o que podemos chamar de dialética dos conceitos.

Após estes esclarecimentos, voltamos à formulação contida nos Tópicos. Para o estagirita, a dialética nada mais é "do que um processo de crítica onde se encontra o caminho que conduz aos princípios de todas as investigações" (Tópicos, 1973, p.11). E esse processo busca solucionar problemas, que nada mais são do que questões sobre as quais os raciocínios se chocam, causando embaraço, por isso necessitam de argumentação. $\mathrm{O}$ falante, ao expor um problema, tenta conduzir o ouvinte a escolher ou rejeitar algo.

Outro ponto que merece destaque neste artigo é o fenômeno denominado contestação ou refutação, ou seja, a demonstração de que uma tese ou afirmação é falsa.

Aristóteles afirma, ainda, que uma das estratégias para refutar uma opinião é reinterpretá-la - ao examinar todos os casos em que se afirmou ou se negou alguma coisa estabelecendo para ela um outro sentido, pois o objetivo maior da dialética é exatamente convencer acerca de uma opinião.

As proposições dialéticas, para Aristóteles, incluem opiniões que são semelhantes às geralmente aceitas e, portanto, admitidas. É válido mencionar que a dialética não tem um compromisso com a verdade absoluta, já que seu campo de trabalho se detém na verossimilhança das coisas. Por isso, dizer meias verdades bem elaboradas e argumentadas pode ter um grau maior de convencimento do que dizer a própria verdade. A utilização das estratégias dialéticas passa então a ser um meio para se alcançar um determinado fim e demonstra uma ordem de mundo essencialmente subjetiva, onde a preferência do sujeito/falante predomina e o objetivo maior é conduzir a uma conclusão.

A dialética é um método utilizado para as chamadas situações de comunicação onde são gerados conflitos. Ela capacita o homem a propor questões e levantar objeções. Diferente da retórica, que almejava persuadir ou entusiasmar multidões em determinadas situações, a dialética torna a palavra uma ferramenta útil aos conflitos diários e, por meio da força expressiva, impõe-se, vencendo todas as resistências ao contrário. É a relação direta ouvinte/falante.

Os gregos consideravam o dom da linguagem uma característica peculiar dos seres humanos e o seu maior traço distintivo em relação aos demais animais. Por isso, para honrar esse privilégio, de ser homem, cada cidadão tinha a obrigação de não só aprender a falar, mas de falar bem. Pois, segundo Aristóteles, "se é lamentável não saber defender-se com o corpo, 
mais lamentável, ainda, é não saber defender-se com a palavra, expressão do exclusivamente humano".

Aos poucos, a dialética, segundo a concepção aristotélica, foi desaparecendo e seu lugar foi sendo ocupado pelo método metafísico, que se opõe, em geral, ao dialético, na medida que entende a natureza e seus reflexos como diferentes e imutáveis. Quando submetidos à investigação, serão de maneira separada e independentes um do outro. A dialética entende que a natureza e seus fenômenos constituem um todo unitário, não podendo ser um dos outros, uma vez que estão em constante mudança. Essa teoria, segundo Leandro Konder (1986), não era bem aceita entre os gregos do período clássico, que não entendiam essa falta de estabilidade na existência de qualquer ser. Por isso preferiam a teoria de Parmênides de que a essência do ser era imutável e aquele fenômeno chamado mudança era superficial. Essa linha de pensamento ficou conhecida como metafísica.

A dialética ficou sufocada pelas transformações sociais e para sobreviver precisou renunciar às suas mais profundas configurações, ora conciliando-se com a metafísica, ora tolhida pelo imperialismo religioso. Embora não tenha desaparecido por completo, só com o transcorrer dos anos e das mudanças sociopolíticas vai ressurgindo gradativamente. Mas ao fim do século XVIII, após a Revolução Francesa, e no começo do século XIX, a dialética ganhou uma nova estruturação e retornou com força através de Imanuel Kant (1724-1804), que centrou seus estudos na questão do conhecimento. Georg Friedrich Hegel (1770-1831) deteve-se na questão dos ser, acreditando que o trabalho, principalmente o intelectual, era a mola que impulsionava o desenvolvimento humano. Karl Marx (1818-1883) se distinguia do seu antecessor por acreditar que o único trabalho útil é o físico, o material. Para a moderna concepção de dialética, o primeiro representante desta forma de argumentação seria Heráclito de Éfeso, que viveu aproximadamente entre 540-480 a.C. Em seus fragmentos - acredita-se que existam cerca de cento e trinta, alguns de origem duvidosa - pode-se ler que tudo existe em constante mudança, e que a lei maior é a do conflito. Um fragmento de Heráclito que ficou famoso e que demonstra a teoria das contradições é o de número 91. Nele se lê que um homem não toma banho duas vezes no mesmo rio, porque d segunda vez não será o mesmo homem, nem o mesmo rio, ambos terão mudado.

A dialética, a partir deste conceito, não é mais considerada um método aplicado ao diálogo, mas é vista como uma ciência que estuda os fenômenos naturais e sociais através de leis consideradas gerais no universo. São elas: a lei da correlação (lei da ação recíproca e da conexão universal), lei da transformação (lei da transformação universal do desenvolvimento incessante), lei da mudança qualitativa e da luta dos contrários. Segundo Konder (1986), ela passa a ser "o modo de pensar, que, ao privilegiar as contradições da realidade, permite que o sujeito se compreenda como agente e colaborador do processo de transformação constante, através do qual todas as coisas existem".

Concluindo, podemos dizer que a dialética foi e continua sendo de suma importância para a sobrevivência do homem, enquanto ser social. Pois, quer como técnica do diálogo ou como princípio da contradição sistemática, adaptando-se a uma realidade cambiante, torna-nos seres com um espírito crítico e autocrítico.

Para exemplificar o método dialético, escolhemos a protagonista da tragédia Antígona de Sófocles. Segundo Maria do Carmo Pandolfo (1977, p.20), o personagem trágico "se constrói na tensão dialetal estabelecida entre a intencionalidade do ato, decorrente da liberdade humana, e a injunção do destino fixado pelos deuses". Esta definição resume perfeitamente o núcleo trágico de Antígona e a tensão dialetal demonstrada pelas falas das personagens.

Embora a argumentação em Antígona esteja dividida em dois blocos: o primeiro com as falas de Antígona e Ismênia, destacando a condição da mulher e o contraste entre a atitude das duas irmãs; o segundo com o diálogo entre Creonte e Antígona e o destaque maior encontra- 
se nas relações de poder; neste artigo só utilizaremos como exemplificação dialética trechos do primeiro bloco, ou seja, do diálogo entre Antígona e sua irmã Ismênia.

Essa divisão em blocos, caracterizando dois momentos de Antígona, demonstra o que Aristóteles define por propriedade temporária (1973, p.79), visto que são decorrentes de fatos particulares que se referem a um período específico. Antígona foge ao padrão estipulado às mulheres de sua época e isto fica bem claro na tragédia homônima através da oposição entre a sua figura e a de sua irmã, Ismênia, que representa a cópia perfeita desse padrão, ou seja, toda a diferença argumentativa entre as duas irmãs está na quebra das referências padronizadas. Antígona contém em si e em seu nome o elemento negativo (anti-agon), próprio da adversidade existente entre ambas. E, embora possuam elos e características comuns, guardam a individualidade marcante da situação de oposição recíproca.

Nos primeiros versos analisados, que vão do 21 ao 39, o autor utiliza o recurso da demonstração, ou seja a protagonista expõe as razões dos seus atos como sendo oriundos do decreto de Creonte em relação ao sepultamento de Polinice. Segundo o tratado aristotélico, os argumentos utilizados nesses versos enfocam três problemas, que nada mais são do que "os temas sobre os quais versam os raciocínios" (1973, p.13). São eles: o direito de Polinice ao sepultamento, a proclamação de Creonte e a postura de Ismênia.

Ismênia contesta a atitude da irmã, na tentativa de induzi-la, para isso utiliza argumentos óbvios, mas convincentes: o seu génos maldito, o domínio físico e psicológico dos homens sobre as mulheres e as consequências que este domínio produz. A esse processo Aristóteles chama de argumentação aditiva:

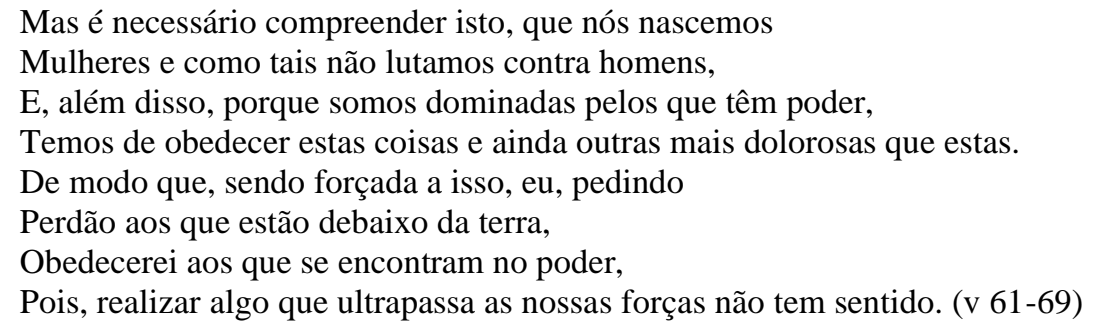

Aristóteles afirma que devemos. Para fazer uma boa argumentação, examinar aqueles casos que "são semelhantes com respeito a uma só coisa" (1973, p.43), e é isso que Ismênia faz ao tentar demonstrar a analogia existente entre o trágico fim de sua família e o que lhe espera, se desobedecer a ordem de Creonte. Ela já está convencida a continuar desempenhando regularmente seu papel, pois ir contra esses argumentos está além de suas forças e por isso "não tem sentido". Com esta atitude, Ismênia resgata o conselho de Péricles na Oração fúnebre que diz: "grande glória vossa será corresponderes a vossa natureza e comentarem os homens o menos possível vossas virtudes e falhas.

Do verso 70 ao 75 Antígona descarta a ajuda de sua irmã e revela, mais claramente, seu ideal heroico - não mais o de Homero de morrer em combate, mas o de morrer por uma causa justa: "eu o sepultarei, para mim será belo morrer fazendo isto" (v.72). E justifica que "seu crime" é piedoso e estimado pelos deuses:

Não te darei mais ordens e nem se, todavia, quisesses fazê-lo, Agirias agradavelmente comigo.

Mas, seja como te parece; eu

O sepultarei. Para mim será belo morrer fazendo isto.

Querida, jazerei junto dele, com quem amo,

Ao cometer um crime piedoso, já que por mais tempo

Eu preciso agradar aos mortos do que aos que estão vivos.

Eu repousarei para sempre no Hades, tu, se te parece bom,

Despreza as coisas que são estimadas pelos deuses (v. 69-70). 
Antígona é guiada por dois princípios básicos: a lei divina e o dever familiar - a lei do sangue. E, se não para todos, pelo menos para Antígona são princípios que têm uma relação de anterioridade e importância superior aos demais. Para Antígona, os seus phíloi se encontram no reino dos mortos, com exceção de Ismênia. Por isso, todo o seu amor e linguagem se manifestam através do culto a estes mortos, que, neste caso, se resume às devidas honras fúnebres, ou no que os gregos chamavam de tà díkaia, ou seja, o direito que todo o mortal tinha à sepultura. Privar um homem desse direito significava condená-lo a vagar cem anos à margem do Stix (principal rio do submundo que separava o mundo dos vivos do mundo dos mortos) e, somado a isso ela iria praticar um crime contra os deuses. Por isso, Antígona rejeita o decreto de Creonte, pois aceitá-lo significaria contribuir para a formação de uma nova "ordem social", que suplantaria a outra, embora não pudesse, culturalmente falando, jamais ser suplantada.

Para atingir seu objetivo utiliza uma frase que exemplifica a oposição dialética morte e vida: "ao cometer um crime piedoso; já que por mais tempo/ eu preciso agradar aos mortos do que aos que estão vivos" (v.75-76).

Para Aristóteles, o herói trágico é aquele que cai no infortúnio por causa de alguma hamartía (Poética, 1453a 10). O erro de Antígona encontra-se no seu protesto solitário contra o Estado e o poder absoluto que ele representa: "Porém eu e minha resolução funesta sofreremos/este malefício, não me deixarei persuadir por nada/tão grande que me faça morrer sem honra" (v. 95-97).

Morrer sem honra... Antígona não admitiria, enquanto heroína, essa hipótese - fato que indicava a importância que os gregos davam ao reconhecimento público de seus feitos - pois a vida, para ela, nada valia sem a honra. Esse pensamento é reforçado por Kitto (1990, p. 40) ao citar: "O que é comum, no homem de alma grande de Aristóteles e no grego médio, é o vivo sentido do seu próprio valor, o desejo de "honra" e de que justiça lhe fosse feita". E somente através do bem agir se produz a virtude e adquire-se a honra.

Antígona defende o seu ponto de vista e põe em evidência todos os conceitos que identifiquem e admitam esse raciocínio. Como sugere Aristóteles, ela utiliza essa estratégia dialética "como um meio para alcançar um fim" (1973, p.35). A lei que ela defende é anterior ao próprio Zeus e à Dike, superior, portanto, aos decretos de qualquer homem e incontestável.

Esse artigo demostra de forma muito suscinta como o método dialético deve e pode ser aplicado nas análises dos discursos. A situação feminina enfocada nesta tragédia, especificamente, serviu, portanto, de quadro de reflexão sobre a prática do discurso feminino antigo, permitindo, ao mesmo tempo, uma visão crítica sobre a sua situação. Toda a abordagem, foi respaldada no que chamamos de argumentação ad hominem, ou seja, dirigida a uma pessoa determinada para lhe refutar as palavras, a discussão realizada através do diálogo, com o objetivo persuasivo.

Tamanha é a força envolvida nas discussões que Aristóteles dedicou-lhe um tratado. Cabe-nos lembrar, para concluirmos, duas afirmações sobre a dialética. A primeira de Ernest Bloch diz que "a dialética não dá 'boa consciência' a ninguém". Sua função não é tornar determinadas pessoas plenamente satisfeitas com elas mesmas. O método dialético nos incita a revermos o passado à luz do que está acontecendo no presente em nome do futuro, o que está sendo em nome do que "ainda não é"; a segunda é do filósofo Antístenes: "Só é livre quem é senhor de si mesmo". Antígona torna-se senhora de si mesma ao quebrar uma regra que corresponde às normas de uma representação social, principalmente ao que diz respeito à disciplina, pois essas regras preservam uma determinada estrutura política. Mas, como tudo aquilo que foge ao padrão, ela também é eliminada. Sófocles, através de uma belíssima oposição dialética, expõe a verdadeira situação de Antígona: "porque sendo piedosa adquiri reputação de impiedosa" (v.923). 
Antígona, aparentemente, consegue convencer os tebanos, embora não consiga a adesão deles ao seu feito, pois a tirania de Creonte os oprimia. Seus argumentos foram "demolidos" pelo que Charaudeaux (1992, p.809) chama de situação de comunicação.

Sófocles converteu o único argumento que Antígona tinha em vários, disfarçando o quanto pôde este processo, mas o dialético é exatamente isso "o homem hábil em propor questões e levantar objeções" (Tópicos, p.158). E, através desse conflito, entre utilitarismo humano e religião, Sófocles estruturou o fim de uma geração maldita: a dos Labdácidas.

\section{REFERÊNCIAS BIBLIOGRÁFICAS}

ARISTÓTELES. Tópicos. São Paulo. Ed. Abril, 1973. Poétique. Paris: Les Belles Lettres, 1979.

CHARAUDEAUX, Patrick. Grammaire du sens et de l'expression. Paris: Hachette, 1992.

HARVEY, Paul. Dicionário Oxforf de literatura clássica - grega e latina. Rio de Janeiro: Jorge Zahar Editor, 1985.

KITTO, H.D.F. A tragédia grega. 2V. Coimbra: Armênio Amado, 1990. Os gregos. Coimbra: Armênio Amado, 1990.

KONDER, Leandro. O que é dialética. São Paulo: Editora Brasiliense, 1986.

LLANOS, Alfredo. Introdução à dialética. Rio de Janeiro: Ed. Civilização Brasileira S.A., 1996.

MURPHY, James J. Sinopsis histórica da argumentação de la retórica clásica. Madrid: Gredos, 1993.

PANDOLFO, Maria do Carmo. Ser ou não ser Antígona. Rio de Janeiro: Imago, Ed. LTDA, 1977.

PERELMAN, Chaïm. Tratado da argumentação - uma nova retórica. São Paulo: Martins Fontes, 1988.

POLITZER, Georges; BESSE, Gui e CAVEING, Maurice. Princípios fundamentais de filosofia. São Paulo: Ed. Hemus, s/d. 